\title{
HUBUNGAN FAKTOR LINGKUNGAN DENGAN RISIKO TERJADINYA ISPA PADA BALITA DI DESA SUKAMUKTI KECAMATAN JALAKSANA KABUPATEN KUNINGAN TAHUN 2021
}

\author{
Syafa Widy Syahaya, Mamlukah, Indrayani \\ STIKes Kuningan \\ widysyahayasyafa@gmail.com
}

\begin{abstract}
Abstrak
Menurut WHO, (2016) jumlah penderita ISPA adalah 59.417 anak. Secara umum terdapat tiga faktor risiko terjadinya ISPA, yaitu faktor lingkungan, faktor individu anak serta faktor perilaku. Faktor lingkungan meliputi: pencemaran udara dalam rumah (asap rokok dan asap hasil pembakaran bahan bakar untuk memasak dengan konsentrasi yang tinggi), ventilasi rumah dan kepadatan hunian. Penelitian ini menggunakan pendekatan penelitian survey (analitik) dengan desain penelitian cross sectional. Variabel dalam penelitian ini yaitu variabel independen meliputi faktor lingkungan dan variabel dependen yaitu risiko terjadinya ISPA. Populasi dalam penelitian ini yaitu sebanyak 334 responden. Sampel dalam penelitian ini simple random sampling sebanyak 85 responden. Lokasi penelitian yaitu di Desa Sukamukti Kecamatan Jalaksana Kabupaten Kuningan pada tahun 2021. Ada hubungan antara kepadatan hunian ( $p$ value $=0,000)$, kelembaban ruangan $(p$ value $=0,000)$, suhu ruangan $(p$ value $=0,000)$, pencahayaan ( $p$ value $=0,001)$, ventilasi $(p$ value $=0,000)$, paparan asap rokok $(p$ value $=0,000)$, dan jenis dinding ( $p$ value $=0,014)$ dengan resiko terjadinya ISPA pada balita di di Desa Sukamukti Kecamatan Jalaksana Kabupaten Kuningan pada tahun 2021.
\end{abstract}

Kata Kunci : Balita, ISPA, Faktor Lingkungan

\section{Pendahuluan}

Infeksi Saluran Pernapasan Akut (ISPA) merupakan salah satu penyakit menular dan penyebab kematian yang paling banyak terjadi pada anak di Negara berkembang dan negara maju (Wulandhani
\& Purnamasari, 2019). Infeksi saluran pernapasan ini menyebabkan 4 dari 15 juta perkiraan kematian pada anak berusia di bawah lima tahun pada setiap tahunnya 
JOURNAL OF HEALTH RESEARCH SCIENCE

VOL. 1 NO. 02, DESEMBER 2021

DOI:

sebanyak dua pertiga kematian tersebut adalah bayi (WHO, 2003).

Menurut World Health Organization WHO, (2016) insiden ISPA di negara seperti Amerika, Afrika dan negara di benua Asia pada tahun 2016 diperkirakan terjadi kematian di atas 40 per 1000 kelahiran hidup adalah $15 \%-20 \%$ per tahun pada golongan usia balita.

Menurut Kementerian Kesehatan Republik Indonesia, (2016) "kasus ISPA mencapai 28\% dengan 533,187 kasus yang ditemukan pada tahun 2016 dengan 18 provinsi diantaranya mempunyai prevalensi di atas angka nasional. Selain itu ISPA juga sering berada pada daftar 10 penyakit terbanyak di rumah sakit dan Puskesmas. Salah satu penyakit yang paling banyak diderita oleh masyarakat adalah ISPA (Infeksi Saluran Pernapasan Akut)".

Secara umum terdapat tiga faktor risiko terjadinya ISPA, yaitu faktor lingkungan, faktor individu anak serta faktor perilaku. Faktor lingkungan meliputi: pencemaran udara dalam rumah (asap rokok dan asap hasil pembakaran bahan bakar untuk memasak dengan konsentrasi yang tinggi), ventilasi rumah dan kepadatan hunian. Faktor individu anak meliputi: umur anak, berat badan lahir, status gizi, vitamin A dan status imunisasi. Faktor perilaku meliputi perilaku pencegahan dan penanggulangan ISPA pada bayi atau peran aktif keluarga/masyarakat dalam menangani penyakit ISPA. Faktor penyebab ISPA pada balita adalah berat badan bayi rendah (BBLR), status gizi buruk, imunisasi yang tidak lengkap, kepadatan tempat tinggal dan lingkungan fisik (Maryunani, 2010).

Penelitian ini diambil di Desa Sukamukti Kecamatan Jalaksana Kabupaten Kuningan karena ada permasalahan terkait faktor lingkungan dengan risiko terjadinya ISPA pada balita seperti kepadatan hunian, kelembaban ruangan, suhu ruangan, pencahayaan, ventilasi, paparan asap rokok, dan jenis dinding. Berdasarkan uraian diatas, maka peneliti tertarik untuk melakukan penelitian yang berjudul "Hubungan Faktor Lingkungan Dengan Risiko Terjadinya ISPA pada balita di Desa Sukamukti Kecamatan Jalaksana Kabupaten Kuningan Tahun 2021”.

\section{Metode}

Penelitian ini menggunakan jenis penelitian (survey) analitik. Survei analitik adalah survei atau penelitian yang mencoba menggali bagaimana dan mengapa fenomena kesehatan itu terjadi, dengan menggunakan metode cross sectional yaitu penelitian untuk mempelajari dinamika 
JOURNAL OF HEALTH RESEARCH SCIENCE

VOL. 1 NO. 02, DESEMBER 2021

DOI:

korelasi antara variabel bebas dan variabel terikat dengan cara pendekatan, observasi atau pengumpulan data sekaligus pada suatu saat (point time approach) artinya setiap subjek penelitian hanya di observasi sekali saja dan pengukuran dilakukan terhadap status karakter atau variabel subjek pada saat pemeriksaan (Notoatmodjo, 2018).
Ciptaan disebarluaskan di bawah Lisensi Creative Commons

Atribusi-NonKomersial-

BerbagiSerupa 4.0 Internasional.
Penelitian ini dilakukan untuk meilhat Faktor-Faktor yang mempenaruhi kejadian ISPA pada balita di Desa Sukamukti Kecamatan Jalaksana Kabupaten Kuningan 2021.

Hasil

Tabel 1 Gambaran Distribusi Frekuensi Responden Berdasarkan Faktor Lingkungan dan Risiko Terjadinya ISPA di Desa Sukamukti Kecamatan Jalaksana Kabupaten Kuningan Tahun 2021

\begin{tabular}{|c|c|c|}
\hline $\begin{array}{ll}\text { Variabel } \\
\end{array}$ & Frekuensi (n) & Total (\%) \\
\hline \multicolumn{3}{|l|}{ Kepadatan Hunian } \\
\hline Tidak Memenuhi Syarat & 57 & 67,1 \\
\hline Memenuhi Syarat & 28 & 32,9 \\
\hline Jumlah & 85 & 100,0 \\
\hline \multicolumn{3}{|l|}{ Kelembaban Ruangan } \\
\hline Tidak Memenuhi Syarat & 55 & 64,7 \\
\hline Memenuhi Syarat & 30 & 35,3 \\
\hline Jumlah & 85 & 100,0 \\
\hline \multicolumn{3}{|l|}{ Suhu Ruangan } \\
\hline Tidak Memenuhi Syarat & 66 & 77,6 \\
\hline Memenuhi Syarat & 19 & 22,4 \\
\hline Jumlah & 85 & 100,0 \\
\hline \multicolumn{3}{|l|}{ Pencahayaan } \\
\hline Tidak Memenuhi Syarat & 63 & 74,1 \\
\hline Memenuhi Syarat & 22 & 25,9 \\
\hline Jumlah & 85 & 100,0 \\
\hline \multicolumn{3}{|l|}{ Ventilasi } \\
\hline Tidak Memenuhi Syarat & 52 & 61,2 \\
\hline Memenuhi Syarat & 33 & 38,8 \\
\hline Jumlah & 85 & 100,0 \\
\hline \multicolumn{3}{|l|}{ Paparan Asap Rokok } \\
\hline Terpapar & 54 & 63,5 \\
\hline Tidak Terpapar & 31 & 36,5 \\
\hline Jumlah & 85 & 100,0 \\
\hline \multicolumn{3}{|l|}{ Jenis Dinding } \\
\hline Tidak Memenuhi Syarat & 17 & 20,0 \\
\hline
\end{tabular}


JOURNAL OF HEALTH RESEARCH SCIENCE

VOL. 1 NO. 02, DESEMBER 2021

DOI:
Ciptaan disebarluaskan di

bawah Lisensi Creative Commons

Atribusi-NonKomersial-

BerbagiSerupa 4.0 Internasional

\begin{tabular}{lcc} 
Memenuhi Syarat & 68 & 80,0 \\
\hline \multicolumn{1}{c}{ Jumlah } & $\mathbf{8 5}$ & $\mathbf{1 0 0 , 0}$ \\
\hline Risiko ISPA & & \\
Berisiko & 53 & 62,4 \\
Tidak Berisiko & 32 & 37,6 \\
\hline \multicolumn{1}{c}{ Jumlah } & $\mathbf{8 5}$ & $\mathbf{1 0 0 , 0}$ \\
\hline
\end{tabular}

Sumber : Data Primer, 2021

Bardasarkan tabel 1, distribusi frekuensi responden berdasarkan Faktor Lingkungan dan Risiko Terjadisnya ISPA, menunjukkan bahwa dari 85 responden, kepadatan hunian paling banyak tidak memenuhi syarat sebanyak 28 responden $(32,9 \%)$. Kelembaban ruangan paling banyak tidak memenuhi syarat yaitu 55 responden $(64,7 \%)$ dan memenuhi syarat sebanyak 30 responden (35,3\%). Suhu ruangan paling banyak tidak memenuhi syarat yaitu 66 responden $(77,6 \%)$ dan memenuhi syarat sebanyak 19 responden $(22,4 \%)$. Pencahayaan paling banyak tidak memenuhi syarat yaitu 63 responden
$(74,1 \%)$ dan memenuhi syarat sebanyak 22 responden $(25,9 \%)$. Ventilasi paling banyak tidak memenuhi syarat yaitu 52 responden $(61,2 \%)$ dan memenuhi syarat sebanyak 33 responden $(38,8 \%)$. Paling banyak terpapar asap rokok yaitu 54 responden $(63,5 \%)$ dan tidak terpapar sebanyak 31 responden (36,5\%). Jenis dinding paling banyak memenuhi syarat yaitu 68 responden $(80,0 \%)$ dan tidak memenuhi syarat sebanyak 17 responden $(20,0 \%)$. Risiko terjadinya ISPA pada balita paling banyak berisiko yaitu 53 responden $(62,4 \%)$ dan tidak berisiko sebanyak 32 responden $(37,6 \%)$.

Tabel 2 Hubungan Faktor Lingkungan dengan Risiko Terjadinya ISPA Pada Balita di Desa Sukamukti Kecamatan Jalaksana Kabupaten Kuningan Tahun 2021

\begin{tabular}{|c|c|c|c|c|c|c|c|c|}
\hline \multirow{3}{*}{ Variabel } & \multicolumn{6}{|c|}{ Risiko Ispa } & \multirow{3}{*}{ P value } & \multirow{3}{*}{ OR $(95 \%$ CI $)$} \\
\hline & \multicolumn{2}{|c|}{ Risiko } & \multicolumn{2}{|c|}{$\begin{array}{c}\text { Tidak } \\
\text { Berisiko } \\
\end{array}$} & \multicolumn{2}{|c|}{ Total } & & \\
\hline & $\mathbf{n}$ & $\%$ & $\mathbf{n}$ & $\%$ & $\mathbf{N}$ & $\%$ & & \\
\hline \multicolumn{9}{|l|}{ Kepadatan Hunian } \\
\hline Tidak Memenuhi Syarat & 48 & 84,2 & 9 & 15,8 & 57 & 100 & \multirow{3}{*}{0,000} & \\
\hline Memenuhi Syarat & $\underline{5}$ & $\underline{17,9}$ & $\underline{23}$ & $\underline{82,1}$ & $\underline{28}$ & $\underline{100}$ & & 24,533 \\
\hline Jumlah & 53 & 62,4 & 32 & 37,6 & 85 & 100 & & $7,383-81,527$ \\
\hline $\begin{array}{l}\text { Kelembaban Ruangan } \\
\text { Tidak Memenuhi Syarat }\end{array}$ & $\begin{array}{c}45 \\
8\end{array}$ & $\begin{array}{l}81,8 \\
26,7\end{array}$ & $\begin{array}{l}10 \\
22\end{array}$ & $\begin{array}{l}18,2 \\
73,3\end{array}$ & $\begin{array}{l}55 \\
30\end{array}$ & $\begin{array}{l}100 \\
100\end{array}$ & 0,000 & $\begin{array}{c}12,375 \\
4,286-35,731\end{array}$ \\
\hline
\end{tabular}


JOURNAL OF HEALTH RESEARCH SCIENCE

VOL. 1 NO. 02, DESEMBER 2021

DOI:
Ciptaan disebarluaskan di

bawah Lisensi Creative Commons

Atribusi-NonKomersial-

BerbagiSerupa 4.0 Internasional.

Memenuhi Syarat

\begin{tabular}{|c|c|c|c|c|c|c|c|c|}
\hline Jumlah & 53 & 62,4 & 32 & 37,6 & 85 & 100 & & \\
\hline \multicolumn{7}{|l|}{ Suhu Ruangan } & \multirow{4}{*}{0,000} & \multirow{4}{*}{$\begin{array}{c}29,900 \\
5,987-139,497\end{array}$} \\
\hline Tidak Memenuhi Syarat & 51 & 77,3 & 15 & 22,7 & 66 & 100 & & \\
\hline Memenuhi Syarat & $\underline{2}$ & $\underline{10,5}$ & $\underline{17}$ & $\underline{89,5}$ & $\underline{19}$ & $\underline{100}$ & & \\
\hline Jumlah & 53 & 62,4 & 32 & 37,6 & 83 & 100 & & \\
\hline \multicolumn{9}{|l|}{ Pencahayaan } \\
\hline Tidak Memenuhi Syarat & 46 & 73,0 & 17 & 27,0 & 63 & 100 & \multirow{3}{*}{0,001} & \\
\hline Memenuhi Syarat & $\underline{7}$ & $\underline{31,8}$ & $\underline{15}$ & $\underline{68,2}$ & $\underline{\underline{22}}$ & $\underline{100}$ & & 5,798 \\
\hline Jumlah & 53 & 62,4 & 32 & 37,6 & 85 & 100 & & $2,018-16,663$ \\
\hline \multicolumn{9}{|l|}{ Ventilasi } \\
\hline Tidak Memenuhi Syarat & 42 & 80,8 & 10 & 19,2 & 52 & 100 & \multirow{3}{*}{0,000} & \\
\hline Memenuhi Syarat & $\underline{11}$ & $\underline{33,3}$ & $\underline{\underline{22}}$ & $\underline{66,7}$ & $\underline{33}$ & $\underline{100}$ & & 8,400 \\
\hline Jumlah & 53 & 62,4 & 32 & 37,6 & 85 & 100 & & $3,091-22,827$ \\
\hline \multicolumn{9}{|l|}{ Paparan Asap Rokok } \\
\hline Terpapar & 43 & 79,6 & 11 & 20,4 & 54 & 100 & \multirow{3}{*}{0,000} & \\
\hline Tidak Terpapar & $\underline{10}$ & $\underline{32,3}$ & $\underline{21}$ & $\underline{67,7}$ & $\underline{31}$ & $\underline{100}$ & & 8,209 \\
\hline Jumlah & 53 & 62,4 & 32 & 37,6 & 85 & 100 & & $3,011-22,377$ \\
\hline \multicolumn{9}{|l|}{ Jenis Dinding } \\
\hline Tidak Memenuhi Syarat & 15 & 88,2 & 2 & 11,8 & 17 & 100 & \multirow{3}{*}{0,014} & \\
\hline Memenuhi Syarat & $\underline{38}$ & $\underline{55,9}$ & $\underline{\underline{30}}$ & $\underline{44,1}$ & $\underline{68}$ & $\underline{100}$ & & 5,921 \\
\hline Jumlah & 53 & 62,4 & 32 & 37,6 & 85 & 100 & & $1,255-27,928$ \\
\hline
\end{tabular}

Sumber : Data Primer, 2021

Berdasarkan Tabel 2 mengenai kepadatan hunian menunjukan bahwa dari 57 responden tidak memenuhi syarat dan berisiko ISPA sebanyak 48 responden $(84,2 \%)$. Berdasarkan hasil uji hipotesis dapat diketahui bahwa nilai $p$ menunjukan angka 0,000 atau $p<0,05$ dengan ini dinyatakan adanya hubungan kepadatan hunian dengan risiko terjadinya ISPA pada balita di Desa Sukamukti Kecamatan Jalaksana Kabupaten Kuningan tahun 2021. Kepadatan hunian yang tidak memenuhi syarat berisiko ISPA 2,5 kali lipat lebih besar dibanding dengan kepadatan hunian yang memenuhi syarat dengan nilai $\mathrm{OR}=$ 2,533; CI 95\% $=7,383-81,527$.

Berdasarkan Tabel 2 mengenai kelembaban ruangan menunjukan bahwa dari 55 responden tidak memenuhi syarat dan berisiko ISPA sebanyak 45 responden $(81,8 \%)$. Berdasarkan hasil uji hipotesis dapat diketahui bahwa nilai $p$ menunjukan angka 0,000 atau $p<0,05$ dengan ini dinyatakan adanya hubungan kelembaban ruangan dengan risiko terjadinya ISPA pada balita di Desa Sukamukti Kecamatan Jalaksana Kabupaten Kuningan tahun 2021. Kelembaban ruangan yang tidak memenuhi 
JOURNAL OF HEALTH RESEARCH SCIENCE

VOL. 1 NO. 02, DESEMBER 2021

DOI:

syarat berisiko ISPA 12,4 kali lipat lebih besar dibanding dengan kelembaban ruangan yang memenuhi syarat dengan nilai $\mathrm{OR}=12,375 ;$ CI $95 \%=4,286-35,731$.

Berdasarkan Tabel 2 mengenai suhu ruangan menunjukan bahwa dari 66 responden tidak memenuhi syarat dan berisiko ISPA sebanyak 51 responden (77,3\%). Berdasarkan hasil uji hipotesis dapat diketahui bahwa nilai $p$ menunjukan angka 0,000 atau $p<0,05$ dengan ini dinyatakan adanya hubungan suhu ruangan dengan risiko terjadinya ISPA pada balita di Desa Sukamukti Kecamatan Jalaksana Kabupaten Kuningan tahun 2021. Suhu ruangan yang tidak memenuhi syarat berisiko ISPA 28,9 kali lipat lebih besar dibanding dengan suhu ruangan yang memenuhi syarat dengan nilai $\mathrm{OR}=28,900$; CI $95 \%=5,987-139,497$.

Berdasarkan Tabel 2 mengenai pencahayaan menunjukan bahwa dari 63 responden tidak memenuhi syarat dan berisiko ISPA sebanyak 46 responden $(73,0 \%)$. Berdasarkan hasil uji hipotesis dapat diketahui bahwa nilai $p$ menunjukan angka 0,001 atau $p<0,05$ dengan ini dinyatakan adanya hubungan pencahayaan dengan risiko terjadinya ISPA pada balita di Desa Sukamukti Kecamatan Jalaksana Kabupaten Kuningan tahun 2021.

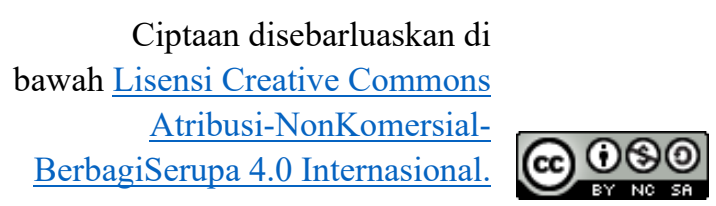

Pencahayaan yang tidak memenuhi syarat berisiko ISPA 5,8 kali lipat lebih besar dibanding dengan pencahayaan yang memenuhi syarat dengan nilai $\mathrm{OR}=5,798$; CI $95 \%=2,018-16,663$.

Berdasarkan Tabel 2 mengenai ventilasi menunjukan bahwa dari 52 responden tidak memenuhi syarat dan berisiko ISPA sebanyak 42 responden $(80,8 \%)$. Berdasarkan hasil uji hipotesis dapat diketahui bahwa nilai $p$ menunjukan angka 0,000 atau $p<0,05$ dengan ini dinyatakan adanya hubungan ventilasi dengan risiko terjadinya ISPA pada balita di Desa Sukamukti Kecamatan Jalaksana Kabupaten Kuningan tahun 2021. Ventilasi yang tidak memenuhi syarat berisiko ISPA 8,4 kali lipat lebih besar dibanding dengan ventilasi yang memenuhi syarat dengan nilai $\mathrm{OR}=8,400 ;$ CI $95 \%=3,091-22,827$.

Berdasarkan Tabel 2 mengenai paparan asap rokok menunjukan bahwa dari 54 responden terpapar asap rokok dan berisiko ISPA sebanyak 43 responden $(79,6 \%)$. Berdasarkan hasil uji hipotesis dapat diketahui bahwa nilai $p$ menunjukan angka 0,000 atau $p<0,05$ dengan ini dinyatakan adanya hubungan paparan asap rokok dengan risiko terjadinya ISPA pada balita di Desa Sukamukti Kecamatan Jalaksana Kabupaten Kuningan tahun 2021. 
JOURNAL OF HEALTH RESEARCH SCIENCE

VOL. 1 NO. 02, DESEMBER 2021

DOI:

Paparan asap rokok berisiko ISPA 8,2 kali lipat lebih besar dibanding dengan tidak terpapar asap rokok dengan nilai $\mathrm{OR}=$ 8,$209 ;$ CI $95 \%=3,011-22,377$.

Berdasarkan Tabel 2 mengenai jenis dinding menunjukan bahwa dari 17 responden tidak memenuhi syarat dan berisiko ISPA sebanyak 15 responden $(88,2 \%)$. Berdasarkan hasil uji hipotesis dapat diketahui bahwa nilai $p$ menunjukan angka 0,014 atau $p<0,05$ dengan ini dinyatakan adanya hubungan jenis dinding dengan risiko terjadinya ISPA pada balita di Desa Sukamukti Kecamatan Jalaksana Kabupaten Kuningan tahun 2021. Jenis dinding yang tidak memenuhi syarat berisiko ISPA 5,9 kali lipat lebih besar dibanding dengan jenis dinding yang memenuhi syarat dengan nilai $\mathrm{OR}=5,921$; CI $95 \%=1,255-27,928$.

\section{Pembahasan}

1. Hubungan Kepadatan Hunian Dengan Risiko Terjadinya ISPA Pada Balita

Berdasarkan hasil uji hipotesis, diketahui bahwa nilai $p$ menunjukan angka 0,000 atau $p<0,05$ dengan ini dinyatakan adanya hubungan kepadatan hunian dengan risiko terjadinya ISPA pada balita di Desa Sukamukti Kecamatan Jalaksana Kabupaten Kuningan tahun 2021.
Ciptaan disebarluaskan di bawah Lisensi Creative Commons Atribusi-NonKomersialBerbagiSerupa 4.0 Internasional.

Hasil penelitian ini sesuai dengan pendapat Notoatmodjo, (2007) yang menyatakan bahwa "untuk ketetapan luas rumah, jumlah dan ukuran ruangan harus disesuaikan dengan jumlah orang yang akan menempati rumah tersebut agar tidak terjadi kelebihan jumlah penghuni rumah. Luas lantai bangunan rumah sehat harus cukup untuk penghuni di dalamnya, artinya luas lantai bangunan tersebut harus sesuai dengan jumlah penghuninya. Luas bangunan yang tidak sebanding dengan penghuninya akan menyebabkan overcrowded. Hal ini akan mengakibatkan dampak buruk bagi kesehatan serta menyebabkan kurangnya konsumsi O2 sehingga berpotensi terhadap penularan penyakit infeksi, artinya jika penghuni terlalu padat bila ada yang sakit maka akan mempercepat penyebaran penularan penyakit seperti yang berhubungan dengan pernapasan yaitu ISPA”.

2. Hubungan Kelembaban Ruangan Dengan Risiko Terjadinya ISPA Pada Balita

Hasil penelitian menunjukkan bahwa ada hubungan antara kelembaban ruangan dengan risiko terjadinya ISPA pada balita di Desa Sukamukti Kecamatan Jalaksana Kabupaten Kuningan. Pada uji Chi Square untuk data 2x2 tidak dijumpai nilai harapan (Expected Count) kurang dari 
JOURNAL OF HEALTH RESEARCH SCIENCE VOL. 1 NO. 02, DESEMBER 2021

DOI:

5 dan tidak lebih dari $20 \%$ jumlah sel diperoleh nilai $p$ value $=0,000$ ( $p$ value $<0,05)$.

Kualitas udara dalam ruangan yang baik didefinisikan sebagai udara yang bebas dari bahan pencemar penyebab iritasi, ketidaknyamanan atau terganggunya kesehatan penghuni. Temperatur dan kelembaban udara dalam ruangan juga dapat mempengaruhi kenyamanan dan kesehatan bagi penghuninya (Keman, 2005). Imunitas balita yang masih rentan terhadap penyakit akan mudah terserang penyakit yang berhubungan dengan saluran pernapasan terutama ISPA jika kelembaban udara dalam kamar yang tidak memenuhi syarat yaitu berkisar antara 40\%-70\%. Sehingga sangat dianjurkan menambah ventilasi alami sebagai sarana pertukaran udara dan diharapkan dapat mengurangi kelembaban udara yang terlalu tinggi.

3. Hubungan Suhu Ruangan Dengan Risiko Terjadinya ISPA Pada Balita

Hasil penelitian berdasarkan uji Odds Ratio diperoleh nilai $\mathrm{OR}=29,9$ yang berarti bahwa suhu rumah merupakan faktor risiko yang bermakna. Hasil penelitian ini menunjukkan hasil yang berbeda dengan hasil penelitian yang dilakukan oleh Sulistyorini et al., (2006) yang menunjukkan bahwa tidak ada hubungan yang bermakna antara suhu rumah dengan kejadian ISPA pada balita.

Penelitian ini sama dengan yang dilakukan oleh Spengler et al., (2011) di Rusia menunjukkan bahwa suhu dalam rumah mempunyai hubungan yang bermakna dengan kejadian pneumonia pada balita. Hasil penelitian menunjukkan bahwa jumlah rumah balita yang suhunya memenuhi syarat lebih besar (58.0 \%) dibanding dengan rumah balita yang tidak memenuhi syarat $(42.0 \%)$.

4. Hubungan Pencahayaan Dengan Risiko Terjadinya ISPA Pada Balita

Hasil penelitian menampilkan bahwa dari $46 \quad(73,0 \%)$ responden yang tidak memenuhi syarat pencahayaan yaitu kurang dari 60 Lux dan tidak menyilaukan mempunyai balita yang menderita penyakit ISPA. Pada uji Chi Square untuk data 2x2 tidak dijumpai nilai harapan (Expected Count) kurang dari 5 dan tidak lebih dari $20 \%$ jumlah sel diperoleh nilai $p$ value $=$ $0,001$ ( $p$ value $<0,05)$.

Salah satu penyebab kurangnya pencahayaan alami yang masuk dalam rumah terutama pada kamar balita adalah karena daerah pemukimannya termasuk padat penduduk sehingga batas antara rumah yang satu dengan yang lain sangat sempit, hasil penelitian ini sejalan dengan hasil 
JOURNAL OF HEALTH RESEARCH SCIENCE

VOL. 1 NO. 02, DESEMBER 2021

DOI:

penelitian Sinaga, (2012). Sehingga, akibatnya adalah memperkecil kemungkinan sinar matahari untuk bisa masuk ke dalam rumah.

5. Hubungan Ventilasi Dengan Risiko Terjadinya ISPA Pada Balita

Pada uji Chi Square untuk data 2x2 tidak dijumpai nilai harapan (Expected Count) kurang dari 5 dan tidak lebih dari $20 \%$ jumlah sel diperoleh nilai $p$ value $=$ $0,000$ ( $p$ value $<0,05)$ yang menunjukkan bahwa ada hubungan antara ventilasi dengan risiko terjadinya ISPA pada balita di Desa Sukamukti Kecamatan Jalaksana Kabupaten Kuningan. Hasil tersebut sesuai dengan penelitian yang dilakukan oleh Pangestika \& Pawenang, (2010, p. 69) yang menunjukkan bahwa adanya hubungan antara luas ventilasi kamar balita terhadap kejadian ISPA pada balita di keluarga pembuat gula aren Desa Pandanarum dan Desa Beji Kecamatan Pandanarum Kabupaten Banjarnegara dengan nilai $p$ value $=0,001(p$ value $<0,05)$.

Penelitian ini juga sejalan dengan yang dilakukan oleh Safitri, (2009, p. 58) yang menunjukkan adanya hubungan antara luas ventilasi dengan kejadian ISPA pada balita di wilayah kerja Puskesmas Jekulo Kudus dengan $p$ value $=0,001$ ( $p$ value $<$ 0,05). Luas ventilasi merupakan salah satu

\section{Ciptaan disebarluaskan di \\ bawah Lisensi Creative Commons \\ Atribusi-NonKomersial \\ BerbagiSerupa 4.0 Internasional.}

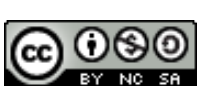

faktor lingkungan yang dapat menjadi faktor risiko penyakit ISPA mempunyai fungsi yang sangat penting yaitu sebagai sarana untuk menjamin kualitas dan kecukupan sirkulasi udara yang keluar dan masuk dalam ruangan.

6. Hubungan Paparan Asap Rokok Dengan Risiko Terjadinya ISPA Pada Balita

Hasil penelitian menunjukkan bahwa ada hubungan antara paparan asap rokok dengan risiko terjadinya ISPA pada balita di Desa Sukamukti Kecamatan Jalaksana Kabupaten Kuningan. Pada uji Chi Square untuk data 2x2 tidak dijumpai nilai harapan (Expected Count) kurang dari 5 dan tidak lebih dari 20\% jumlah sel diperoleh nilai $p$ value $=0,000$ ( $p$ value $<0,05)$.

Merokok merupakan salah satu faktor risiko penting untuk beberapa penyakit termasuk ISPA. Hasil penelitian menunjukkan bahwa sebagian besar anggota keluarga yang mempunyai kebiasaan merokok adalah kepala rumah tangga. Risiko asap rokok bagi perokok pasif dewasa dapat terkena kanker paru-paru, bayi yang dikandung oleh ibu perokok pasif berpotensi mempunyai kelainan, dan anakanak dari perokok lebih rentan terhadap infeksi saluran pernapasan (Sumartono, 2008). 
JOURNAL OF HEALTH RESEARCH SCIENCE

VOL. 1 NO. 02, DESEMBER 2021

DOI:

7. Hubungan Jenis Dinding Dengan Risiko Terjadinya ISPA Pada Balita

Penelitian yang dilakukan menemukan sebagian besar dari sampel secara keseluruhan telah memiliki dinding rumah yang memenuhi syarat. Rumah yang memiliki dinding yang memenuhi syarat tersebut memiliki dinding tembok dan juga papan yang kemudian dilapisi dengan triplek. Dan pada rumah yang tidak memenuhi syarat masih memiliki dinding yang terbuat dari papan yang tidak rapat/jarang. Berdasarkan uji statistik yang dilakukan, diperoleh nilai $p>0,05(0,014)$ dan dapat disimpulkan bahwa ada hubungan yang signifikan antara jenis dinding dengan risiko terjadinya ISPA pada balita.

Hal ini tidak sejalan dengan penelitian yang dilakukan oleh Lingga et al., (2014) yang menemukan bahwa "tidak ada hubungan antara jenis dinding dengan kejadian ISPA pada balita". Dan hal yang mempengaruhi kejadian ISPA pada balita adalah kebersihan dinding dan kerapatan dinding. Dinding yang kurang rapat dapat menyebabkan penumpukan debu pada dinding yang sering terjadi pada rumah yang berdinding papan.

\section{Kesimpulan}

\section{Ciptaan disebarluaskan di bawah Lisensi Creative Commons Atribusi-NonKomersial- BerbagiSerupa 4.0 Internasional.}

Berdasarkan hasil analisis maka dapat disimpulkan ada hubungan antara kepadatan hunian ( $p \quad$ value $=0,000)$, kelembaban ruangan ( $p$ value $=0,000)$, suhu ruangan $(p$ value $=0,000)$, pencahayaan $(p$ value $=0,001)$, ventilasi ( $p$ value $=0,000)$, paparan asap rokok ( $p$ value $=0,000)$, dan jenis dinding $(p$ value $=0,014)$ dengan resiko terjadinya ISPA pada balita di di Desa Sukamukti Kecamatan Jalaksana Kabupaten Kuningan pada tahun 2021.

\section{Saran}

Adapun saran bagi responden yaitu melakukan kebiasaan untuk membuka jendela agar sirkulasi udara lancar dan udara dapat masuk sehingga kelembaban dapat berkurang dan selalu menjaga kebersihan lingkungan rumah dan melaksanakan perilaku hidup bersih dan sehat (PHBS).

\section{Daftar Pustaka}

Keman, S. (2005). Soedjajadi Keman, Kesehatan Perumahan. Jurnal Kesehatan Lingkungan Universitas Airlangga, 2.

Kementerian Kesehatan Republik Indonesia. (2016). Profil Kesehatan Indonesia 2016. In Profil Kesehatan Provinsi Bali. http://www.depkes.go.id/resources/do wnload/pusdatin/profil-kesehatanindonesia/Profil-Kesehatan-Indonesia2016.pdf 
JOURNAL OF HEALTH RESEARCH SCIENCE

VOL. 1 NO. 02, DESEMBER 2021

DOI:

Lingga, R. N., Nurmaini, N., \& Santi, D. N. (2014). Hubungan Karakteristik Rumah dengan Kejadian Ispa pada Balita dalam Keluarga Perokok di Kelurahan Gundaling I Kecamatan Berastagi Kabupaten Karo Tahun 2014. https://www.neliti.com/id/publications /14534/hubungan-karakteristik-rumahdengan-kejadian-ispa-pada-balitadalam-keluarga-per

Maryunani, A. (2010). Ilmu Kesehatan Anak dalam Kebidanan. Trans Info Media. https://www.belbuk.com/ilmukesehatan-anak-dalam-kebidanan-p22694.html

Notoatmodjo, S. (2007). Kesehatan Masyarakat Ilmu dan Seni. In Rineka Cipta. Rineka Cipta.

Notoatmodjo, S. (2018). Metodologi Penelitian Kesehatan. Rineka Cipta.

Pangestika, Y. R., \& Pawenang, E. T. (2010). Hubungan kondisi lingkungan terhadap kejadian ISPA pada balita keluarga pembuat gula aren. KEMAS: Jurnal Kesehatan Masyarakat, 5(2).

Safitri, L. R. (2009). Hubungan antara Kondisi Fisik Rumah dengan Kejadian ISPA pada Balita di Wilayah Kerja Puskesmas Jekulo Kudus. Skripsi, Semarang: Universitas Negeri Semarang.

Sinaga, E. R. K. author. (2012). Kualitas Lingkungan Fisik Rumah Dengan Kejadian ISPA Pada Balita Di Wilayah Kerja Puskesmas Kelurahan Warakas Kecamatan Tanjung Priok Jakarta

\author{
Ciptaan disebarluaskan di \\ bawah Lisensi Creative Commons \\ Atribusi-NonKomersial- \\ BerbagiSerupa 4.0 Internasional.
}

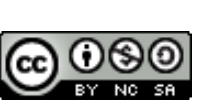

Utara Tahun 2011. Universitas Indonesia. http://lib.ui.ac.id

Spengler, J. D., Jaakkola, J. J. K., Parise, H., Katsnelson, B. A., Privalova, L. I., \& Kosheleva, A. A. (2011). Housing Characteristics And Children's Respiratory Health In The Russian Federation.

Https://Doi.Org/10.2105/AJPH.94.4.6 57, 94(4), 657-662. https://doi.org/10.2105/AJPH.94.4.657

Sulistyorini, L., Sukamawa, A., \& Keman, S. (2006). Determinan Sanitasi Rumah dan Sosial Ekonomi Keluarga terhadap Kejadian Ispa pada Anak Balita Serta Manajemen Penanggulangannya di Puskesmas. Jurnal Kesehatan Lingkungan Unair, 3(1), 3966.

Sumartono, W. (2008). Stop Merokok Sebab Anda Bisa. Jakarta: Sagung Seto.

WHO. (2003). Indikator Perbaikan Kesehatan Lingkungan Anak (E. A. Hardiyanti (ed.); 1st ed.). EGC. https://books.google.co.id/books?id=E pgpZ2Hjkm0C

WHO. (2016). World Health Statistics 2016: Monitoring Health for The SDGs, Sustainable Development Goals.

Wulandhani, S., \& Purnamasari, A. B. (2019). Analisis Faktor Risiko Kejadian Infeksi Saluran Pernapasan Akut ditinjau dari Lingkungan Fisik. Sainsmat: Jurnal Ilmiah Ilmu Pengetahuan Alam, 8(2), 70. https://doi.org/10.35580/sainsmat8210 7212019 